\title{
An Active Helideck Testbed for Floating Structures based on a Stewart-Gough Platform
}

\author{
Alexandre Campos, Jacqueline Quintero, Roque Saltarén, Manuel Ferre and Rafael Aracil
}

\begin{abstract}
A parallel robot testbed based on Stewart-Gough platform called Active-helideck is designed, developed and tested as a helicopter floating helideck. The objective of this testbed is to show the advantages of helicopters that use an active helideck upon landing on and taking off from ships or from offshore structures. Active-helideck compensates simulated movements of a ship at sea. The main goal of this study is to maintain the robot's end effector (helideck) in a quasi-static position in accordance to an absolute inertial frame. Compensation is carried out through the coordinate action of its six prismatic actuators in function of an inertial measurement unit. Moreover, the simulation of the sea movement is done by a parallel robot called ship platform with three degrees of freedom. The ship platform is built with a vertical oscillation along the $z$ axis, i.e. heave, and rotates on remaining axes, i.e. roll and pitch. Active helideck is able to compensate simulated movements by considering the ship as an inertial frame as observed in the experiment.
\end{abstract}

\section{INTRODUCTION}

Offshore flight operations, mainly landing and taking off are complex processes that require high levels of training, competence and skill even in good weather flying conditions. These operations can be seriously affected by adverse weather or present surrounding effects around installations, vessels or helidecks. Wind and waves are main weather factors at offshore structures.

Wind over the deck and wave turbulence shed by the ship's super structure create challenging and unpredictable conditions during takeoff and landing. Any movement of the sea can produce pitch, roll, yaw, and/or heave at the helideck. Different sea conditions make vessels behave in different manners due to their size, hull design, stabilization systems etc. A helicopter pilot operating at such platforms must observe heave, pitch, and roll motion of the landing platform and determine landing contact time based on human timing reaction as well as aircraft performance [1]. Environmental effects happen when the wind is blown out from funnels. Hot exhaust gases from the combustion motors could affect air temperature around or above helidecks. Gradients in air temperature and/or velocity above helidecks could cause additional problems to taking off and landing helicopters.

In order to assist crew in such difficult maneuvers or task, different strategies have been implemented to determine wind and wave measurements more precisely on board a ship.

The first author is supported by Spanish Ministerio de Educación (MEC) under Programa Juan de la Cierva. The second author belongs to Universidad Tecnolgica de Panamá and is funded by Senacyt - Panamá.

Authors are with the Department of Automática, Ing. Electrónica e Inf Industrial, Universidad Politécnica de Madrid, Spain.

E-mail: acamposeetsii.upm.es

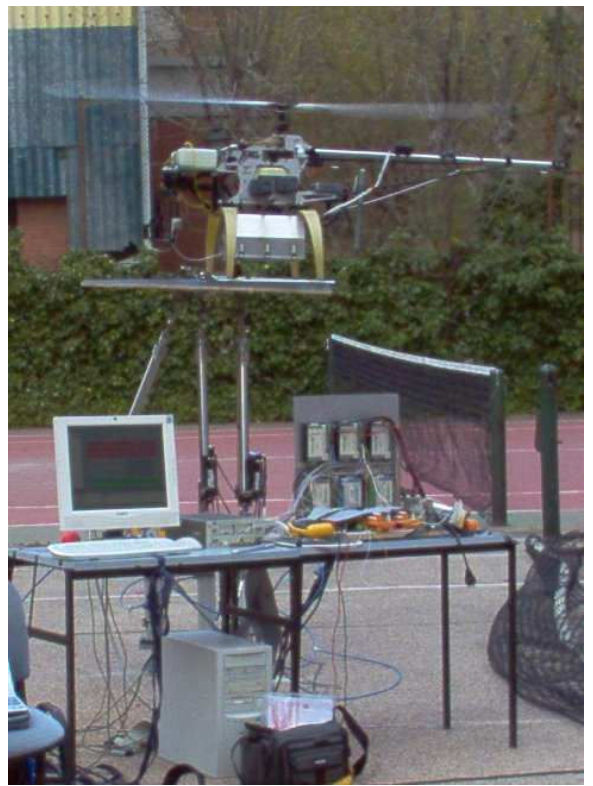

Fig. 1. Testbed: active helideck (AH) and ship platform (SP)

Mathematical models for ship movements are formulated [2], [3]. Wave measurement using pressure sensors, horizontal radars, vertically operating distance or velocity meter, and analysis with fast communication systems have been developed [4]. Moreover, by means of a satellite (e.g. ERS-1 European Remote-Sensing Satellite-1), wind and wave fields, sea-surface temperature, ocean tides, iceberg monitoring, oil and pollution detection can be determined. Satellite measurements combined with wave model give real time wave information for sea operation [5], [4]. Furthermore, an aircraft/ship dynamic interface analysis simulation software package has been developed in order to analyze dynamic interface that exists between ships and embarked aircraft. It has been extensively validated and applied [6], [7].

Computer simulations are some approaches done for studying this case. Oh et al. design an autopilot for autonomous helicopter landing on a rocking ship through a tether in helideck (target) tracking [8]. In this case, a controller is considered to ensure the landing of a helicopter on a ship based on measurement of angle between the helicopter/ship and the cable. Dalamagkidis et al. design a gimbaled landing platform on an unmanned ground vehicle. Instead of a ship, an unmanned ground vehicle is used in order to transport miniature vertical take off and landing 


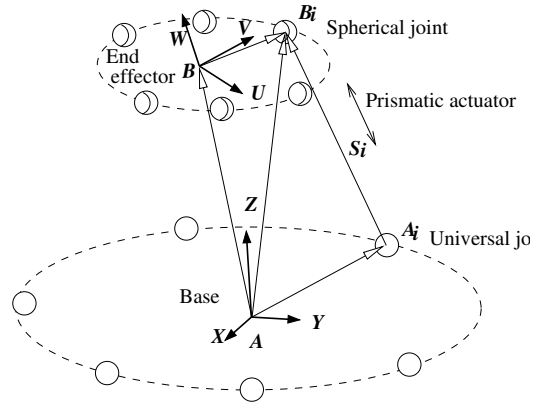

Fig. 2. Schematic architecture of the 6-dof parallel robot used as active helideck

(VTOL) vehicles to its target area serving as an on site take off/landing and/or possibly as a refueling base [9].

Therefore, development of new equipment and technologies are required so as to ease helicopter crew with the execution of flight operation. At present, a new approach using an active helideck has been presented. Its aim is to compensate possible movements of a landing platform caused by wind and/or waves. A 6-dof parallel robot has been designed, simulated and built. Its objective is to test active helideck on a moving structure. A ship at sea movement simulator called ship platform has been designed and built. Three more important offshore structure movements: roll, pitch and heave [2], are considered; therefore a 3 dof parallel platform [12], two of rotation and one of movement along the vertical axis have been used as a ship platform.

Firstly, this paper describes the testbed description, i.e. active helideck and ship platform as shown in Fig. 1. Secondly, kinematics model and control strategy for the testbed are explained. It is then followed by the experimental procedure and results. Lastly, conclusions are pointed out.

\section{TESTBED DESCRIPTION}

In order to compensate helideck movement with the wind and wave effects on the ship's hull, as well as simulating this movement in the testbed, some dimension considerations have taken into account.

The application presented in this paper, position amplitude is $0.1 \mathrm{~m}$ in position, orientation amplitude is $6^{\circ}$ and wave period is $10 \mathrm{~s}$. Orientation angle and the wave period were taken from RMS values of general operability limiting criteria for ships [14]. On the other hand, a big ship has been considered in order not to take into account scaling factors in terms of size and mass/inertia properties or transients due to helicopter landing/taking off for this testbed.

The testbed in this study is based on a parallel robot architecture, i.e. a closed kinematics chain. A 6 dof StewartGough platform is selected for the active helideck [10], [11] as shown in Fig. 2.

Stewart Platforms are mainly used for flight or driving simulators [15] and for machine tools [16], [17]. The advantages of Stewart Platforms are the excellent weight and payload capability ratio and precise positioning [11]. A Stewart platform is commonly used in obtaining acceleration,

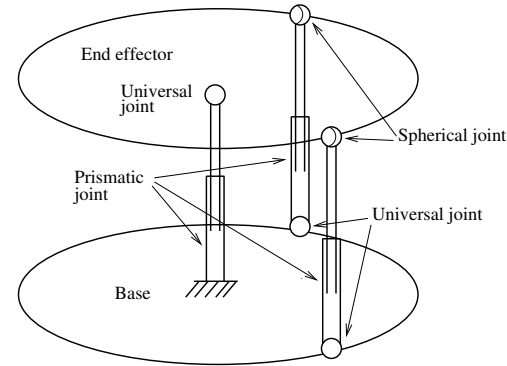

Fig. 3. Schematic architecture of the 3-dof parallel robot used as ship movement simulator

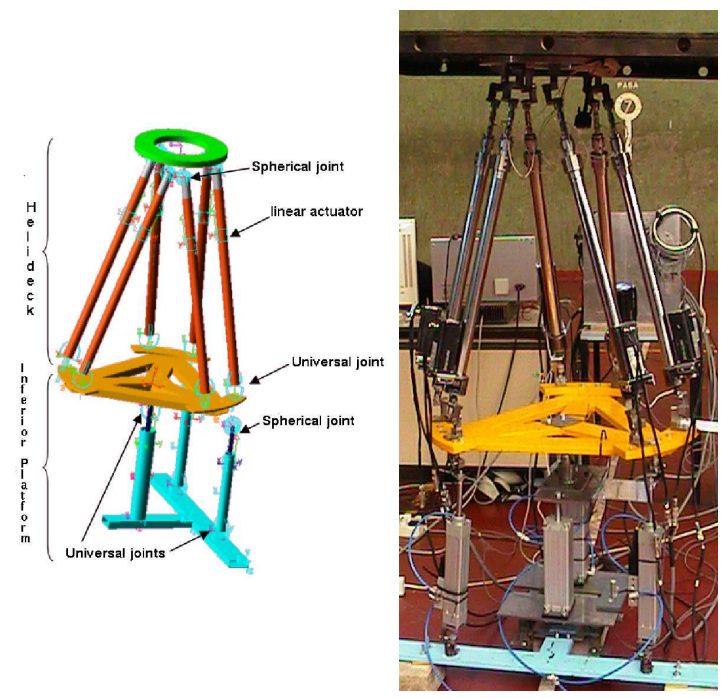

Fig. 4. Testbed for computational simulation and for real testing

but it can also generate an anti acceleration if the base platform is moving [18]; application of Stewart platforms compensate acceleration of a moving robot. However, only vibrations of relatively minimal amplitude are considered [18], [19], [20], [21]. A greater amplitude is considered in vibration control simulation of a Stewart-Gough platform on flexible suspension [22], where the platform compensates the movements of a radio telescope mounted at a suspending structure. In such case, expected wind-induced vibration can be as high as $0.5 \mathrm{~m}$ in position and $3^{\circ}$ in orientation. In this given case, the reaction force caused by the motion of the stabilized platform will lead to perturbation on the base platform as the base platform is not fixed on the ground. It will then induce vibration on the whole system.

Aiming at simulating the ship movement, the closed kinematic chain used is the 3-dof parallel manipulator shown in Fig. 3.

In this paper, the proposed alternative is a testbed compounded by two main parts, see Fig. 4, the ship platform from now on named $\mathbf{S P}$, i.e. a ship at sea movement simulator, and the active helideck from now on named $\mathbf{A H}$, i.e. a StewartGough platform. 


\section{A. Active helideck}

The active Helideck (AH) is a Stewart-Gough platform 6-UPS (Universal, Prismatic, Spherical) whose end effector (helideck) is connected to the base, i.e. SP end effector, through six prismatic electrical actuators. Prismatic actuators are connected to the end effector by spherical joints and to the base by universal joints. Ballscrews actuated by electric brush-less motors have been used considering prismatic movement.

\section{B. Ship platform}

The SP requires that its platform end effector (base of AH) moves along vertical axis ( $Z$ ), taking into account ship movement heave, rotation around axes $X$ and $Y$ with respect to its base, and also roll and pitch from ship movements. Therefore, a 3dof parallel platform is constructed which consists of four pneumatic prismatic actuators respectively controlled by proportional valves:

- Two pneumatic cylinders fixed to the base that are connected by a universal joint to the end effector (ship hull). These cylinders move simultaneously in order to control height, i.e. heave of the SP end effector. These two cylinder are cinematically considered as one central cylinder.

- Two pneumatic cylinders provide the rotational movements, i.e. roll and pitch; these cylinders, called external cylinders, are connected by universal joints to the base and by spherical joints to the end effector.

Therefore, AH compensates the movement of the SP in order to maintain the deck, placed on its end effector, in a quasi-static position. The constructed testbed is shown in Fig. 4.

Two sensors are installed on the testbed in order to obtain the information from the environment which allow actuating the $\mathbf{A H}$ conveniently. An inertial measurement unit (IMU) is located at the SP end effector in order to get its instantaneous orientation, through Euler parameters. An ultrasonic length sensor is used to quantify SP height that has to be compensated in order to keep the helideck in a quasi-static height.

\section{KINEMATIC MODEL}

Using the concepts of the parallel robot inverse kinematics, control signals can be obtained in order to determine $\mathbf{A H}$ coordinate movements according SP behavior. This inverse kinematics calculates the limb lengths, which is reached through the active prismatic joints (see Fig. 2), given the SP location (position and orientation).

\section{A. Mathematical tools}

Two Cartesian coordinate systems are attached to base and moving platform in order to calculate parallel robot inverse kinematics. Frames $A(X, Y, Z)$ and $B(U, V, W)$ respectively as shown in Fig. 2.

Each joint location in the base is described by the position vector $A_{i}$ in the coordinate frames $A$. Similarly, each joint location in the end effector is described by the position vector

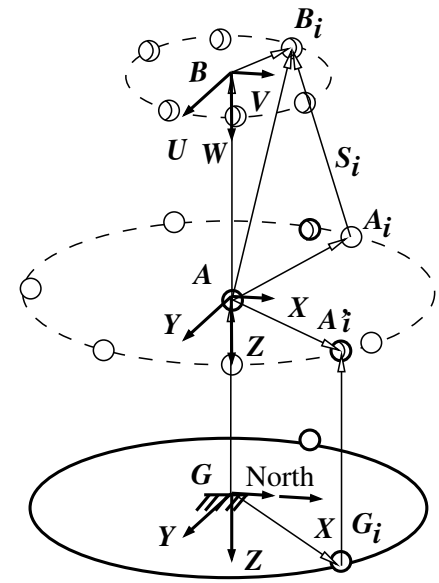

Fig. 5. Reference frames fixed at experimental platform

$B_{j}$ in the coordinate frame $B$. Therefore, the $i$-th limb length is the magnitude of the vector directed from $A_{i}$ to $B_{i}$, i.e. $S_{i}$ :

$$
d_{i}=\left|S_{i}\right|=B_{i}-A_{i}
$$

In order to carry out the vectorial subtraction of (1), the vectors must be expressed in the same reference frame. A point $p$ expressed in reference frame $B$ may be expressed in reference frame $A$, using the matrix of homogeneous transformation [23]:

$$
{ }^{A} T_{B}=\left[\begin{array}{cc}
{ }^{A} R_{B(3 \times 3)} & { }^{A} q_{(3 \times 1)} \\
\gamma_{(1 \times 3)} & \rho_{(1 \times 1)}
\end{array}\right]
$$

Then using the matrix of homogeneous transformation, the position in the new reference frame is obtained by:

$$
\begin{aligned}
{ }^{A} p & ={ }^{A} T_{B}{ }^{B} p \\
{ }^{A} p & ={ }^{A} q+{ }^{A} R_{B}{ }^{B} p
\end{aligned}
$$

where, ${ }^{A} p=\left[p_{x}, p_{y}, p_{z}, 1\right]^{T}$ is the position, in homogeneous coordinates, expressed in reference frame $A$ and ${ }^{B} p=$ $\left[p_{u}, p_{v}, p_{w}, 1\right]^{T}$ is the position in homogeneous coordinates as expressed in reference frame $B$.

\section{B. Testbed kinematic model}

Three reference frames are selected in the testbed: global reference frame $G$, located at the $\mathbf{S P}$ base; reference frame $A$ located at the SP end effector (or $\mathbf{A H}$ base), and the reference frame $B$ located at $\mathbf{A H}$ end effector, see Fig. 6. Initially these frames are oriented according the IMU axes as ruled by: $X$ axis yields along magnetic north direction and $Z$ axis aligns to gravitational force direction. The IMU is attached to the SP end effector. It is used to measure its orientation through the four Euler parameters $\left(e_{0}, e_{1}, e_{2}, e_{3}\right)$.

The coordinates of the universal joint axes that connect the prismatic actuators at $\mathbf{A H}$ end effector are determined in a Cartesian coordinates system relative to reference frame $B$. The points where the $\mathbf{A H}$ actuators are attached to their base $\left(A_{i}\right)$ are specified on reference frame $A$. Additionally, the points where the SP pneumatic cylinders are attached to the $\mathbf{A H}$ base $\left(A_{i}^{\prime}\right)$ are specified on reference frame $A$ too. 
Finally, the points $G_{i}$ where pneumatic cylinders are attached to $\mathbf{S P}$ base (ground) are specified on reference frame $G$, as shown in Fig. 5.

Using this model and the suitable homogeneous transformation matrix, eq. (2), the length of the SP and AH prismatic joints for a given, respectively, SP and $\mathbf{A H}$ end effector position and orientation following the presented procedure can be obtained.

\section{Control Strategy}

The objective of this control strategy is to determine SP and $\mathbf{A H}$ displacements; in such a way that $\mathbf{S P}$ represents the sea movements that has to be compensate by $\mathbf{A H}$ aiming at a quasi-static deck. A schematic diagram for the experimental platform is presented in Fig. 6.

\section{A. Ship platform strategies of movement}

Ship movements are described through sinusoidal displacements for the pistons. It is important to notice that the central cylinder determines the ship hull heave. The combination of central and external cylinders determines the ship hull pitch and roll.

Displacement of the SP central cylinder is sinusoidal around a initial position and independent from the two external cylinders. This displacement causes the desired heave for the SP. External cylinders move follow a sinusoidal displacement too.

Control loop for the SP movement is closed with the IMU attached in the $\mathbf{S P}$ end effector and with the ultrasonic length sensor which measures the SP end effector height.

The rotation matrix is obtained by using values provided by IMU, the reference frame $A$ origin position is $[0,0, z]$ with respect to reference frame $G$, where $z$ is read by a ultrasonic sensor, and the origin position of the reference frame $B$, i.e. the desired deck height, has to be well-known and it is indeed a variable to control.

Through the inverse kinematics, effective displacements that must be reached to obtain the desired total displacement of the actuator are calculated in accordance to current position and orientation of the SP. The sinusoidal movements of the external actuators are out of phase in order to provide movement around $X$ axis, i.e. pitch. The central piston is out of phase in order to obtain oscillations around the $y$ axis, i.e. roll.

\section{B. Active helideck strategies of movement}

The helideck end effector is required to remain in a constant position and orientation with respect to the inertial frame $G$. Aiming at such, it is then necessary to calculate the AH actuator displacements according to the instantaneous SP position and orientation. Nevertheless, applying the equations of inverse kinematics, $\mathbf{A H}$ end effector position has to be determined with respect to the reference frame $G$. Using (2), transformation of coordinates are calculated:

$$
{ }^{A} P_{f}=\left[\begin{array}{ccc}
{ }^{A} R_{G} & { }^{A} P_{G} \\
0 & 0 & 0
\end{array}\right]\left[\begin{array}{c}
{ }^{G} P_{f} \\
1
\end{array}\right]
$$

where,

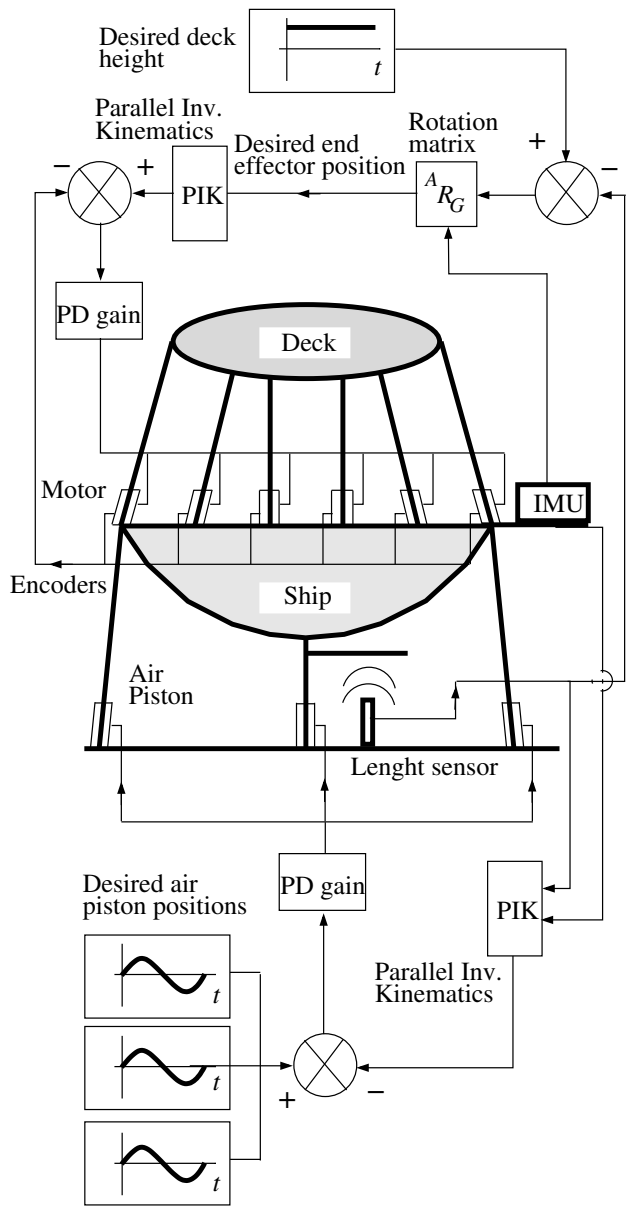

Fig. 6. Testbed schematic diagram

${ }^{G} P_{f} \quad$ is the helideck end effector position with respect to inertial reference frame $G$. This value is maintained constant for any movement of inferior platform.

${ }^{A} P_{G}$ is the position of the frame $G$ with respect to frame $A$. This position is obtained by:

$$
{ }^{A} P_{G}={ }^{A} R_{G}\left(-{ }^{G} P_{A}\right)
$$

${ }^{A} R_{G}$ is the rotation matrix of frame $G$ respect to frame $A$. This it is obtained transposing the rotation matrix ${ }^{G} R_{A}$.

Finally, AH actuator lengths are calculated by using parallel inverse kinematics (IPK).

\section{Position control}

Control stage is based on a dSPACE tm DS1103 card. DS1103 is a digital signal processor (DSP) on a PC platform where the controller can be easily programmed. The control law is introduced in $\mathrm{C}$ environment, then compiled and downloaded to DS1103 card using real time tools included in the Control desk package [25]. The controller card captures voltage signals from inertial measure unit, length sensor and motor encoders. It also calculates every three millisecond 


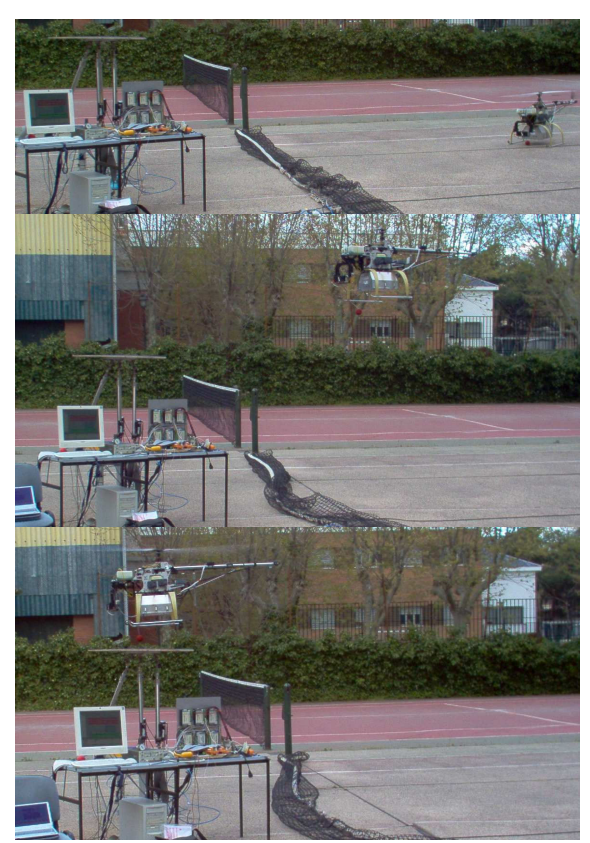

Fig. 7. Helicopter approaching and landing on Helideck

new control signal and feeds the motor amplifiers and the air piston proportional valves.

Control position for both platforms (i.e. SP and $\mathbf{A H}$ ) is performed through proportional derivative PD controllers so as to assure stability even with errors in steady state. These PD gains for electric motors and for pneumatic proportional valves are tuned experimentally. It is important to consider that due compressive air properties, air pistons' behavior is different when moving up or moving down. Therefore, two different PD gains are set to each pneumatic piston.

\section{EXPERIMENTAL TESTS}

The tests have been carried out on the experimental platform in the laboratory and then in field as have been shown in sequence of Fig. 7. This test is required to verify that the helideck (AH end effector) remains quasi-static in spite of SP movements.

Initially, a trajectory planner is used for moving the helideck to a position that allows the actuator movements aiming at compensating the inferior platform movements at any moment. During this time the inferior platform pneumatic actuators are locked.

Then, external pneumatic cylinders are driven in order to carry out SP to a horizontal position. At that moment AH control is activated to compensates the $\mathbf{S P}$ movement. Then, all the pneumatic cylinders are moved to the middle of their strokes and begin a sinusoidal movement. This movement causes a variation in inferior platform orientation and position, which is measured by the sensors. From the sensors information, the processor calculates the AH actuators' displacement needed to hold its fixed location with respect to the inertial frame. Using this information, the
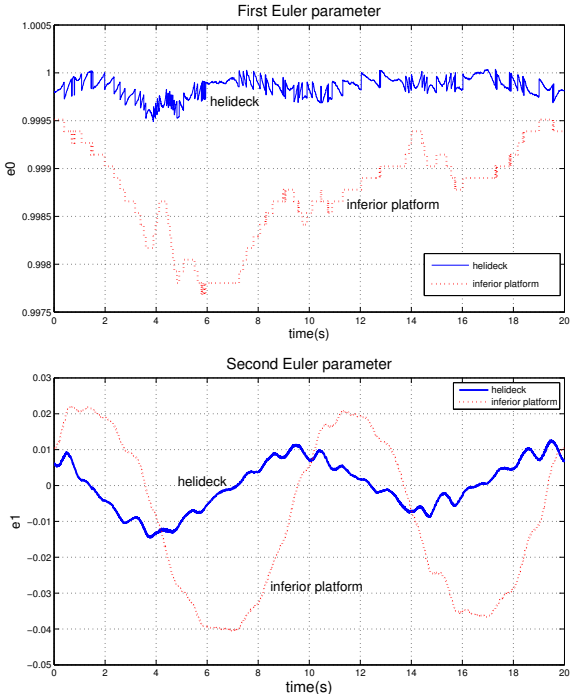

Third parameter

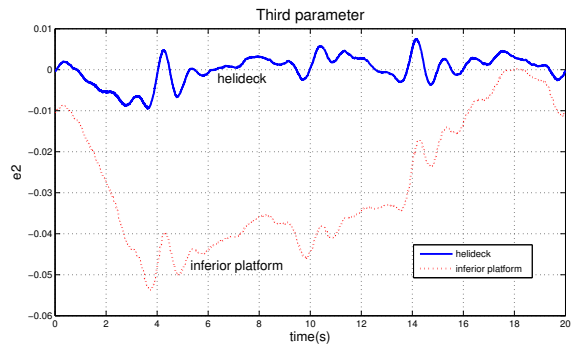

Fig. 8. Euler parameters $\left(e_{0}, e_{1}, e_{2}\right)$ for helideck and $\mathbf{S P}$

actuators are energized through the amplifiers. After that the helicopter approaches and lands on compensated helideck.

Finally, the position and orientation of helideck and inferior platform are compared in order to observe the compensation and the deck's desired behavior.

\section{A. Experimental results}

From the experimental results, the position and orientation variation between helideck and inertial frame can be observed.

The orientation is described through Euler parameters $\left(e_{0}, e_{1}, e_{2}\right.$ and $\left.e_{3}\right)$, where $e_{0}$ is associated to the rotation angle around the axis whose $X, Y$ and $Z$ components are associated to $e_{1}, e_{2}$ and $e_{3}$.

From Fig. 8, SP presents an angular oscillation around $X$ (roll) and $Y$ (pitch) axis representing the sea movement.Additionally, the helideck orientation remains quasistatic in relation to the inertial frame in spite of the orientation variation of its base, i.e. the SP. It is important to highlight that the desired reference Euler parameters, for a horizontal deck position, are $e_{0}=1$ and $e_{1}=e_{2}=e_{3}=0$.

In Fig. 9 is shown the helideck displacement with respect to SP aiming at remaining quasi-static with respect to inertial frame as desired. AH has to compensate the vertical movements as well. Last plot of Figs. 9 shows the helideck behavior for a given wave input, represented by inferior 

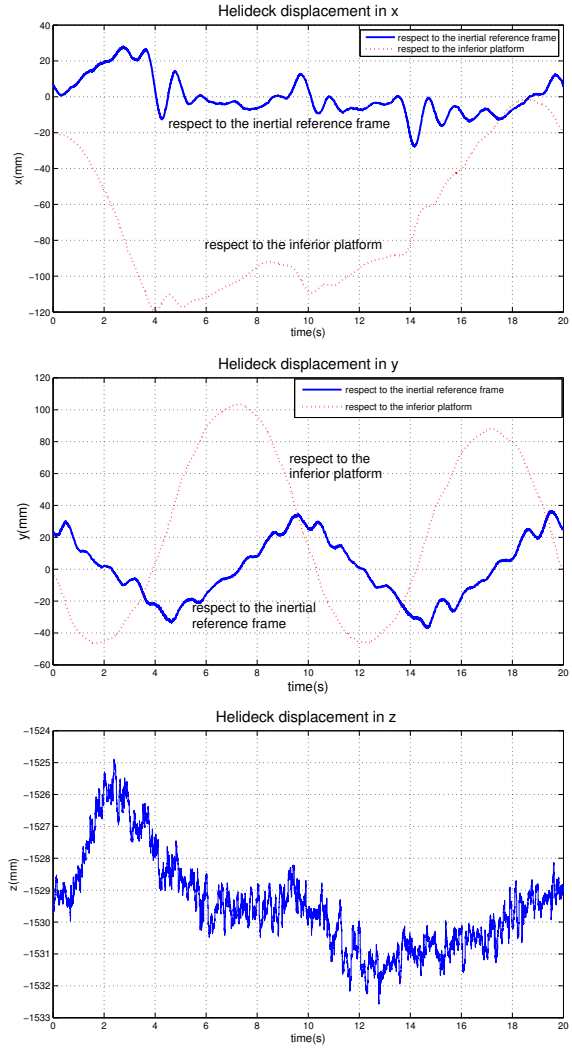

Fig. 9. $X, Y$ and $Z$ position coordinates for helideck with respect to $\mathbf{S P}$ and to inertial frame.

platform vertical movement. It is worth mentioning that the noise in the signal is caused by the use of the ultrasonic length sensor.

\section{CONCLUSIONS AND FUTURE WORKS}

A testbed based on Stewart-Gough platform has been used, built and tested as helicopter deck.

It was observed through experimental test that the active helideck is able to compensate the simulated movement provided by the sea to a ship or off-shore structure in order to ease helicopter landing and take-off maneuvers, considering a big enough ship with inertial frame properties.

The Stewart-Gough platform used in this study can still be improved with a larger base diameter so that the desired helideck angles and height could be attained. However, active helideck inertia due the ship platform motion could decrease.

A dimensional analysis for ship mass/inertia could be done in order to closely simulate a real ship's behavior.

\section{REFERENCES}

[1] T. Ford, M. Hardesty, M. Bobye, Helicopter ship board landing system, in: ION GNSS 18th International Technical Meeting of the Satellite Division, Long Beach, CA, 2005, pp. 979 - 988.

[2] T. Fossen, Marine Control Systems: Guidance, Navigation and Control of Ships, Rigs and Underwater Vehicles, Marine Cybernetics AS, Trondheim, Norway, 2002.
[3] J. Matusiak, Two-stage approach to determination of large amplitude motions of a rigid ship in waves, in: E. Lund, N. Olhoff, S. J. (Eds.), 15th Nordic Seminar in Computational Mechanics - NSCM15, Aalborg, Denmark, 2002, pp. 1 - 10.

[4] P. Pajala, Wave measurements, Maritime Institute of Finland, Sjkulla, Finland, 2002.

[5] Y. He, Z. Jinping, Ocean wave spectrum reconstruction from e s1 satellite scatterometer data, in: IEEE (Ed.), Remote Sensing - A Scientific Vision for Sustainable Development, Vol. 1 of Geoscience and Remote Sensing, 1997 - IGARSS '97, IEEE, 1997, pp. 356 358.

[6] D. Linn, R. Langlois, Development and experimental validation of a shipboard helicopter on-deck manoeuvring simulation, Jornal of Aircraft 43 (4) (2006) 895 - 906.

[7] R. G. Langlois, M. LaRosa, T. A. R., Development, validation, and application of the dynaface helicopter/ship dynamic interface simulation software package, in: SCSC (Ed.), Summer Computer Simulation Conference, Vol. 1, 2003, pp. 356 - 358.

[8] S. Oh, H. Pota, K. Pathak, S. Agrawal, Autonomous helicopter landing on a moving platform using a tether, in: Proceedings - ICRA, Barcelona, 2005, pp. $3960-3965$.

[9] K. Dalamagkidis, S. Ioannou, K. Valavanis, E. Stefanakos, A mobile landing platform for miniature vertical take-off and landing vehicles, in: 14th Mediterranean Conference on Control and Automation - MED '06, IEEE, Barcelona, 2006, pp. 1 - 6.

[10] D. Stewart, A platform with six degrees of freedom, Proceedings of the Institution of Mechanical Engineers 180 (15) (1966) 371-386.

[11] J. Merlet, Parallel Robots, Kluwer Academic Publisher, 2000.

[12] H. Cheng, Real-time manipulation of a hybrid serial-and-paralleldriven redundant industrial manipulator, Journal of dynamic systems measurement and control-transactions of the ASME 116 (4) (1994) $687-701$.

[13] C. Tischler, A. Samuel, K. Hunt, Selecting multi-freedom multi-loop kinematic chains to suit a given task, Mechanism and Machine Theory 36 (8) (2001) 925-938.

[14] Nordforsk'1987. The Nordic Cooperative Project. Seakeeping performance of Ships. Assesment of a ship performance in a seaway. Trodheim, Norway: Marintek, (1987)

[15] M. Baret, Six degrees of freedom large motion system for flight simulators, piloted aircraft environment simulation techniques, in: Piloted aircraft environment simulation techniques, no. 249 in 1 , AGARD Conference Proceeding, Bruxelles, 1978, pp. 22-1/22-7.

[16] F. Pierrot, M. Marquet, O. Company, T. Gil, H4 parallel robot: modeling, design and preliminary experiments, in: Proceedings ICRA, IEEE, Seoul, 2001, pp. 3256-3261.

[17] U. Thomas, I. Maciuszek, F. Wahl, A unified notation for serial, parallel, and hybrid kinematic structures, in: Proceedings - ICRA, Vol. 3, IEEE, Washington, 2002, pp. 2868-2873.

[18] R. Graf, R. Dillmann, Active acceleration compensation using a stewart-platform on a mobile robot, in: E. 97 (Ed.), in Proceedings of the 2nd Euromicro Workshop on Advanced Mobile Robots, Brescia, Italy, 1997 , pp. $59-64$.

[19] Z. Geng, L. Haynes, 6-degree-of-freedom active vibration isolation using a stewart platform mechanism, Journal of Robotic Systems 10 (5) (1993) $725-744$

[20] R. Cobb, J. Sullivan, A. Das, L. Davis, T. Hyde, T. Davis, Z. Rahman, J. Spanos, Vibration isolation and suppression system for precision payloads in space, Smart Materials and Structures 8 (6) (1999) 798 812.

[21] L. Vaillon, B. Petitjean, B. Frapard, D. Lebihan, Active isolation in space truss structures: from concept to implementation, Smart Materials and Structures 8 (6) (1999) 781 - 790.

[22] G. Cheng, Y.and Ren, S. Dai, Vibration control of gough-stewart platform on flexible suspension, Robotics and Automation, IEEE Journal of [see also IEEE Transactions on Robotics and Automation] 19 (3) (2003) $489-493$.

[23] L.-W. Tsai, Robot Analysis: the Mechanics of serial and parallel manipulators, John Wiley \& Sons, New York, 1999.

[24] L. Sciavicco, B. Siciliano, Modeling and Control of Robot Manipulators, The McGraw Hill Companies, Inc., 1996.

[25] dSpace GmbH, DS1103 PPC Control Board Hardware Reference, Germany, 2001. 